\title{
DIRECT TORQUE CONTROL OF MATRIX CONVERTER FED INDUCTION MOTOR DRIVE
}

\author{
Suresh M. ${ }^{1}$, Karpagam. ${ }^{2}$, Nirmal Kumar.A. ${ }^{3}$ \\ 1,2Department of EEE, Bannari Amman Institute of Technology, Sathyamangalam, TamilNadu. \\ ${ }^{3}$ Department of EEE, Info Institute of Engineering, Coimbatore, TamilNadu.
}

\begin{abstract}
This paper presents the direct torque control of induction motor drive using matrix converters. DTC is a high performance motor control scheme with fast torque and flux responses. However, the main disadvantage of conventional DTC is electromagnetic torque ripple. In this paper, direct torque control for Induction Motors using Matrix Converters is analysed and points out the problem of the electromagnetic torque ripple which is one of the most important drawbacks of the Direct Torque Control. Besides, the matrix converter is a single-stage ac-ac power conversion device without dc-link energy storage elements. Matrix converter (MC) may become a good alternative to voltage-source inverter (VSI). This work combines the advantages of the matrix converter with those of the DTC technique, generating the required voltage vectors under unity input power factor operation. Simulation results demonstrates the effectiveness of the torque control.
\end{abstract}

Keywords: Direct Torque control, vector control, Matrix Converters, space vector modulation.

\section{INTRODUCTION}

For many years, induction machine[6,8] have provided the most common form of electromechanical drive for industrial, commercial and domestic applications that can operate at essentially constant speed. Induction machines have simpler and more rugged structure, higher maintainability and economy than DC motors. They are also robust and immune to heavy loading.

In the mid 1980's, a new advanced control technique, known as direct torque and flux control (DTFC or DTC) or direct self-control (DSC) [6] was introduced for voltage-fed PWM inverter drives. However, some research is still being done to adapt DTC to new motors and converters and also to reduce the torque ripple [1, 4] which is one of its main drawbacks. DTC, as the name indicates, is the direct control of torque and flux of a drive by the selection, through a look-up table, of the inverter voltage space vectors. The main advantage of DTC is its structure simplicity, since no coordinate transformations and no PWM generation are needed. However, torque and flux modulus values and the sector of the flux are needed. Not only it is a very simple and robust signal processing scheme but also a very quick and precise torque control response is achieved. Recently, three phase Matrix Converters (MC) have emerged to become a good alternative to the well known Voltage
Source Inverter (VSI)[2,10] due to its advantages over voltage source inverters.

In this paper, a new control technique for matrix converters which generates, under unity input power factor conditions, the voltage vectors needed to implement the DTC for induction motors is investigated. Simulation results, which demonstrate the effectiveness of the proposed scheme, are presented. The results obtained states a good torque response and minimized torque ripples.

\section{DIRECT TORQUE CONTROL THEORY}

The principle of Direct Torque Control (DTC) is to directly select voltage vectors according to the difference between reference and actual value of torque and flux linkage. Torque and flux errors are compared in hysteresis comparators. Depending on the comparators, a voltage vector is selected from a table. Advantages [6] of the DTC are ; low complexity, no pulse width modulation is needed, no co-ordinate transformations needed. Instead one of the six VSI voltage vectors is applied during the whole sample period. All calculations are done in a stationary reference frame which does not involve the explicit knowledge of rotor position. Still, for a synchronous motor, rotor position must be known at start-up.

The DTC hence require low computational power when implemented digitally. The system possess good dynamic performance but shows quite poor 
performance in steady-state since the crude voltage selection criteria give rise to high ripple levels in stator current, flux linkage and torque. Its simplicity makes it possible to execute every computational cycle in a short time period and use a high sample frequency. For every doubling in sample frequency, the ripple will approximately halve. The problem is that the power switches used in the inverter impose a limit for the maximum sample frequency.

In general, a scalar control technique called Volts/hertz control being among the simplest control methods. It is used where exact torque and flux control is not essential but where speed control is desirable, like when several motors are driven in parallel by a single inverter. Vector control is used where high performance torque and flux control is needed. Vector control can be implemented by using FOC or DTC technique. DTC technique is simple, robust and offer good dynamic performance. FOC technique gives the best performance in terms of ripples level but requires more processor power and are more complicated to implement.

\section{DIRECT TORQUE CONTROL PRINCIPLE}

In the direct torque control principles, it has been proven that the change of torque can be controlled by keeping the amplitude of the stator flux linkage constant and increasing the rotating speed of the stator flux linkage as fast as possible [6]. The amplitude and rotating speed of the stator flux linkage can be controlled by selecting the proper stator voltage vectors. Direct torque control (DTC) is one method used in variable frequency drives to control the torque (and thus finally the speed) of three-phase AC electric motors. This involves calculating an estimate of the motor's magnetic flux and torque based on the measured voltage and current of the motor.

The torque expression can be expressed in the vector form as,

$$
\bar{T}_{e}=\frac{3}{2}\left(\frac{P}{2}\right) \bar{\varphi}_{s} \overline{X I}_{S}
$$

where

$$
\begin{aligned}
& \bar{\varphi}_{s}=\varphi_{q s}^{s}-j \varphi_{d s}^{s} \\
& \text { and } \bar{l}_{s}=i_{q s}^{s}-j i_{d s}^{s}
\end{aligned}
$$

In this equation, $\bar{l}_{S}$ is to be replaced by the rotor flux $\bar{\varphi}$. In the complex form, $\bar{\varphi}_{s}$ and $\bar{\varphi}_{r}$ can be expressed as the functions of currents as

$$
\begin{aligned}
& \bar{\varphi}=L_{s} I_{s}+L_{m} \bar{I}_{r} \\
& \bar{\varphi}=L_{r} \bar{I}_{r}+L_{m} \bar{I}_{s}
\end{aligned}
$$

Eliminating $\bar{I}_{r}$ from equation $\bar{\varphi}_{S}$, we get

$$
\bar{\varphi}_{s}=\frac{L_{m}}{I_{r}} \bar{\psi} u b r+L_{s}^{\prime} \bar{I}_{s}
$$

where

$$
L_{s}^{\prime}=L_{s} L_{r}-L_{m}^{2}
$$

The corresponding equation of $\bar{l}_{S}$ is

$$
\bar{I}_{s}=\frac{\varphi_{s}}{L_{s}^{\prime}}-\frac{L_{m}}{L_{r} L_{s}^{\prime}} \bar{\varphi}_{r}
$$

On substituting $\bar{I}_{s}$ in $\bar{T}_{e}$ and further simplification which yields,

$$
\bar{T}_{e}=\frac{3}{2}\left(\frac{P}{2}\right) \frac{L_{m}}{L_{r} L_{s}^{\prime}} \bar{\varphi}_{r} X \bar{\varphi}_{s}
$$

that is, the magnitude of torque is,

$$
T_{e}=\frac{3}{2}\left(\frac{P}{2}\right) \frac{L_{m}}{L_{r} L_{s}^{\prime}}\left|\varphi_{r}\right|\left|\varphi_{s}\right| \sin \gamma
$$

where $\gamma$ is the angle between the fluxes.

If the rotor flux remains constant and the stator flux is changed incrementally by the stator voltage and the corresponding change of $\gamma$ angle is $\Delta \gamma$, the incremental torque expression $\Delta T_{e}$ is given as

$$
\Delta T_{e}=\frac{3}{2}\left(\frac{P}{2}\right) \frac{L_{m}}{L_{r} L_{s}^{\prime}}\left|\varphi_{H}\right|\left|\varphi_{s}+\Delta \bar{\psi}_{s}\right| \sin \Delta \gamma
$$

\section{MATRIX CONVERTER}

Nowadays Matrix Converters are being alternative for Voltage Source Inverters, which converts AC-AC supply without any intermediate dc link. The Matrix Converter is an advanced circuit topology capable of converting AC-AC, providing generation of load voltage with arbitrary amplitude and frequency, bidirectional power flow, sinusoidal input/output waveforms, and operation with unity input power factor. Furthermore, 
since no inductive or capacitive elements are required, matrix converter allows a very compact design. A Matrix Converter is an AC-AC converter, with $m \times n$ bidirectional switches, which connects an m-phase voltage source to an $n$-phase load. From a practical point of view, the three-phase matrix converters having $3 \times 3$ switches connects a three phase voltage source to a three-phase load, e.g. a motor.

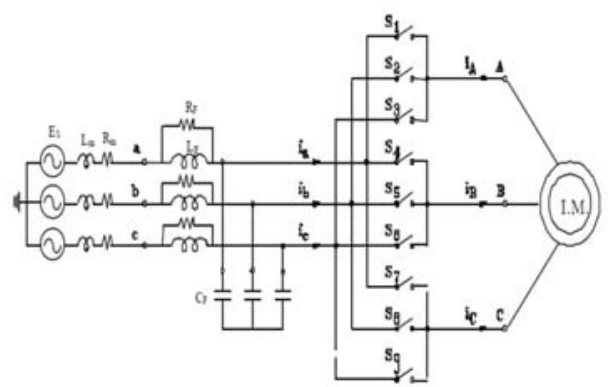

Fig. 1. Three Phase Matrix Converters

In the $M C$ shown in fig.1, a switch $S_{i j} i=i\{A, B, C\}, j=\{a, b, c\}$ can connect phase $i$ of the input to phase jof the load. With a suitable switching strategy, arbitrary voltages $V_{j N}$ at arbitrary frequency can be synthesized. Switches are characterized by the following equation:

$$
S_{i j}=0 \text {, if } S_{i j} \text { is open and }
$$$$
\text { , is } \oint_{i} \varsigma_{i j} \text { is closed. }
$$

The induction motor drive fed by matrix converter is superior to the induction motors fed by the conventional inverters because of the lack of bulky direct current (dc)-link capacitors with limited lifetime, bidirectional power flow capability, sinusoidal input/output currents and adjustable input power factor.

A mathematical model of the MC can be derived as follows:

Applying Kirchhoff's voltage law, (12) can be easily obtained.

$$
\left[\begin{array}{l}
V_{a n(t)} \\
V_{b n(t)} \\
V_{c n t}
\end{array}=\left[\begin{array}{lll}
S_{A n(t)} & S_{B a(t)} & S_{C a(t)} \\
S_{A b(t)} & S_{B b(t)} & S_{C b(t)} \\
S_{A C(t)} & S_{B C(t)} & S_{C a(t)}
\end{array}\right]\left[\begin{array}{l}
V_{A N(t)}(12) \\
V_{B N(t)} \\
V_{C N(t)}
\end{array}\right.\right.
$$

Applying Kirchhoff's current law, it can be found that

$$
\left[\begin{array}{c}
i_{A t)} \\
i_{B(t)} \\
i_{C(t)}
\end{array}\right]=\left[\begin{array}{lll}
S_{A a(t)} & S_{A b(t)} & S_{A c(t)} \\
S_{B a(t)} & S_{B b(t)} & S_{B c(t)} \\
S_{C a(t)} & S_{C b(t)} & S_{C c(t)}
\end{array}\right]\left[\begin{array}{l}
l_{a(t)} \\
l_{b(t)} \\
I_{c(t)}
\end{array}\right]
$$

where the output voltages and output currents are being synthesised by the input voltages and input currents respectively.

\section{SPACE VECTORS OF MATRIX CONVERTER}

It can be noted that the three-phase MC allows any output phase to be connected to any input phase. Thus, 27 switching configuration are possible. Applying Clark's transformation to the 27 possible switching configuration, it can be easily found that a MC can generate 18 active, voltage and current space vectors, three zero vectors and six rotating vectors [13]. Table 1 shows the 27 switching states of the three phase MC. The first 18 states $( \pm 1, \pm 2, \pm 3, \pm 4, \pm 5, \pm 6, \pm 7, \pm 8, \pm 9)$ corresponds to the active vectors. $0 a, 0 b$ and $0 c$ are the corresponding zero vectors states. And the last six states (shadowed rows) are the rotating vectors. Representation of the output line-to-neutral voltages and input line currents space active vectors are shown in fig.2

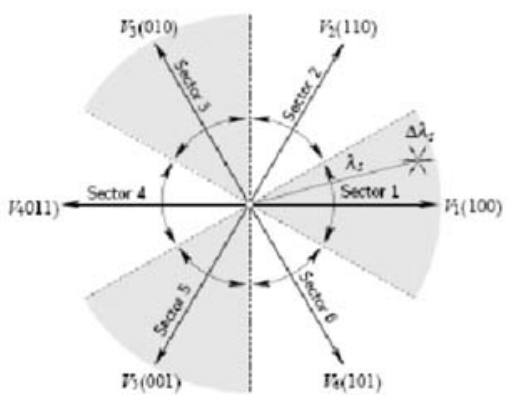

Fig. 2. Space Vectors of Matrix Converters

Fig.2 shows the space vectors for the Matrix Converters. The magnitude and direction of the active vectors depends upon the instantaneous line-to-neutral voltages and line currents as shown in Table 2. The direction of each of these vectors remains constant. On the contrary, the magnitude of the six rotating vectors remains constant and corresponds to the maximum value of the input line-to-neutral voltage vector and the input line current vector, while its direction depends on the angles of the line-to neutral input voltage vector $\alpha_{i}$ and the input line current vector. Fig. 3 shows the vector rotations of Matrix Converters, which is used for the vector selection. 


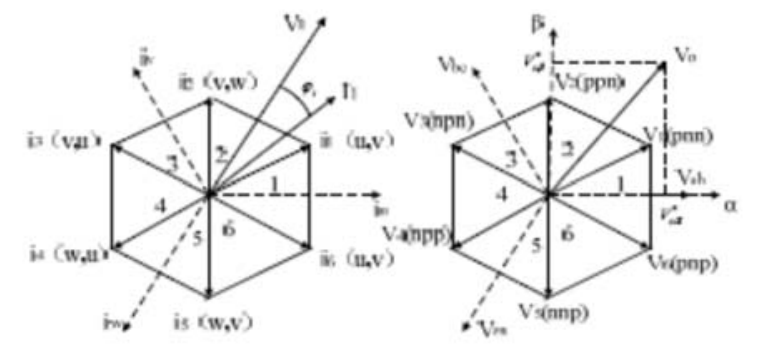

Fig. 3. Rotation of Space Vectors

Table.1 Switching Table for Matrix Converters

\begin{tabular}{|c|c|c|c|c|c|c|c|}
\hline State & A & B & $C$ & $V_{0}$ & $\alpha_{0}$ & $t_{i}$ & $\beta_{1}$ \\
\hline+1 & $a$ & $b$ & $b$ & $+2 / 3 V_{A B}$ & 0 & $2 / \sqrt{3} i_{a}$ & $-\pi / 6$ \\
\hline-1 & $b$ & $\bar{a}$ & $\bar{a}$ & $-2 / 3 V_{A B}$ & 0 & $2 / \sqrt{3} i_{a}$ & $-\pi / 6$ \\
\hline+2 & $b$ & $c$ & $c$ & $+2 / 3 V_{B C}$ & 0 & $2 / \sqrt{3} i_{a}$ & $\pi / 2$ \\
\hline-2 & $c$ & $b$ & $b$ & $-2 / 3 V_{B C}$ & 0 & $2 / \sqrt{3} i_{a}$ & $\pi / 2$ \\
\hline+3 & $c$ & $a$ & $a$ & $+2 / 3 V_{C A}$ & 0 & $2 / \sqrt{3} i_{a}$ & $7 \pi / 6$ \\
\hline-3 & $a$ & $c$ & $c$ & $-2 / 3 V_{C A}$ & 0 & $2 / \sqrt{3} i_{a}$ & $7 \pi / 6$ \\
\hline+4 & $b$ & $a$ & $b$ & $+2 / 3 V_{A B}$ & $2 \pi / 3$ & $2 / \sqrt{3} i_{a}$ & $-\pi / 6$ \\
\hline-4 & $a$ & $b$ & $a$ & $-2 / 3 V_{A B}$ & $2 \pi / 3$ & $2 / \sqrt{3} i_{a}$ & $-\pi / 6$ \\
\hline+5 & $c$ & $b$ & C & $+2 / 3 V_{B C}$ & $2 \pi / 3$ & $2 / \sqrt{3} i_{a}$ & $\pi / 2$ \\
\hline-5 & $b$ & $c$ & $b$ & $-2 / 3 V_{B C}$ & $2 \pi / 3$ & $\pi / 2$ & $2 / \sqrt{3} i_{a}$ \\
\hline+6 & a & $c$ & a & $+2 / 3 V_{C A}$ & $2 \pi / 3$ & $2 / \sqrt{3} i_{a}$ & $7 \pi / 6$ \\
\hline-6 & $c$ & $a$ & $c$ & $-2 / 3 V_{C A}$ & $2 \pi / 3$ & $2 / \sqrt{3} i_{a}$ & $7 \pi / 6$ \\
\hline+7 & $b$ & $b$ & $a$ & $+2 / 3 A B$ & $4 \pi / 3$ & $2 / \sqrt{3} i_{a}$ & $-\pi / 6$ \\
\hline-7 & $a$ & $a$ & $b$ & $-2 / 3 A B$ & $4 \pi / 3$ & $f \sqrt{3}$ isul & $-\pi / 6$ \\
\hline
\end{tabular}

\begin{tabular}{|c|c|c|c|c|c|c|c|}
\hline+8 & $\mathrm{c}$ & $\mathrm{c}$ & $\mathrm{b}$ & $+2 / 3 B C$ & $4 \pi / 3$ & $2 / \sqrt{3}$ isub $\pi / 2$ \\
\hline-8 & $\mathrm{~b}$ & $\mathrm{~b}$ & $\mathrm{c}$ & $-2 / 3 B C$ & $4 \pi / 3$ & $\pi / 2$ & \\
\hline+9 & $\mathrm{a}$ & $\mathrm{a}$ & $\mathrm{c}$ & $+2 / 3 \mathrm{CA}$ & $\begin{array}{c}4 \pi / 3 \\
2 / \sqrt{3}\end{array}$ & $7 \pi / 6$ & \\
\hline-9 & $\mathrm{c}$ & $\mathrm{c}$ & $\mathrm{a}$ & $-2 / 3 \mathrm{CA}$ & $\begin{array}{c}4 \pi / 3 \\
2 / \sqrt{3} i_{a}\end{array}$ & $7 \pi / 6$ & \\
\hline $0_{\mathrm{a}}$ & $\mathrm{a}$ & $\mathrm{a}$ & $\mathrm{a}$ & 0 & - & 0 & -- \\
\hline $0_{\mathrm{b}}$ & $\mathrm{b}$ & $\mathrm{b}$ & $\mathrm{b}$ & 0 & - & 0 & - \\
\hline $0_{\mathrm{c}}$ & $\mathrm{c}$ & $\mathrm{c}$ & $\mathrm{c}$ & 0 & - & 0 & - \\
\hline+10 & $\mathrm{a}$ & $\mathrm{b}$ & $\mathrm{c}$ & $V_{\max }$ & $\alpha_{i}+0$ & $I_{\max }$ & $\beta_{i}+0$ \\
\hline-10 & $\mathrm{a}$ & $\mathrm{c}$ & $\mathrm{b}$ & $V_{\max }$ & $-\alpha_{i}-0$ & $I_{\max }$ & $-\beta_{i}-0$ \\
\hline+11 & $\mathrm{c}$ & $\mathrm{a}$ & $\mathrm{b}$ & $V_{\max }$ & $\alpha_{i}+2 \pi / 3$ & $I_{\max }$ & $\beta_{i}+2 \pi / 3$ \\
\hline-11 & $\mathrm{~b}$ & $\mathrm{a}$ & $\mathrm{c}$ & $V_{\max }$ & $-\alpha_{i}-2 \pi / 3$ & $I_{\max }$ & $-\beta-2 \pi / 3$ \\
\hline+12 & $\mathrm{~b}$ & $\mathrm{c}$ & $\mathrm{a}$ & $V_{\max }$ & $\alpha_{i}+4 \pi / 3$ & $I_{\max }$ & $\beta_{i}+4 \pi / 3$ \\
\hline-12 & $\mathrm{c}$ & $\mathrm{b}$ & $\mathrm{a}$ & $V_{\max }$ & $-\alpha_{i}-4 \pi / 3$ & $I_{\max }$ & $-\beta_{i}-4 \pi / 3$ \\
\hline
\end{tabular}

\section{DTC USING MATRIX CONVERTERS}

Matrix Converters generates a higher number of output voltage vectors with respect to a VSI, the introduction of a third variable, such as the average value of the sine of the displacement angle $\varphi_{i}$ between the input line current vector and the input line to neutral voltage vector, can be used to keep under control of the input power factor. The flux, torque and the average value of sine $\varphi_{i}$ estimations require the knowledge of voltages and currents at the input and output side of the MC. Assuming that $V_{o}$ is the output voltage vector selected by the basic DTC control algorithm, from table 1 , it is obvious that one of the switching states $\pm 1, \pm 2$ or \pm 3 must be selected. Since the magnitude and direction of these voltage vectors depends on the input line-to-neutral voltage vector, only those having the same direction of $V_{i}$ and the maximum magnitude will be taken into consideration. 
Table 2. Switching table for DTC using Matrix Converters

\begin{tabular}{|c|c|c|c|c|c|c|c|c|c|c|c|c|}
\hline & \multicolumn{2}{|c|}{1} & \multicolumn{2}{c|}{2} & \multicolumn{2}{c|}{3} & \multicolumn{2}{c|}{4} & \multicolumn{2}{c|}{5} & \multicolumn{2}{c|}{6} \\
\hline$\phi$ & +1 & -1 & +1 & -1 & +1 & -1 & +1 & -1 & +1 & -1 & +1 & -1 \\
\hline V1 & -3 & 1 & 2 & -3 & -1 & 2 & 3 & -1 & -2 & 3 & 1 & -2 \\
\hline V2 & 9 & -7 & -8 & 9 & 7 & -8 & -9 & -7 & 8 & -9 & -7 & 8 \\
\hline V3 & -6 & 4 & 5 & -6 & -4 & 5 & 6 & -4 & -5 & 6 & 4 & -5 \\
\hline V4 & 3 & -1 & -2 & 3 & 1 & -2 & -3 & 1 & 2 & -3 & -1 & 2 \\
\hline V5 & -9 & 7 & 8 & -9 & -7 & 8 & 9 & -7 & -8 & 9 & 7 & -8 \\
\hline V6 & 6 & -4 & -5 & 6 & 4 & -5 & -6 & 4 & 5 & -6 & 4 & 5 \\
\hline
\end{tabular}

\section{SIMULATION RESULTS AND DISCUSSION}

Fig.4 shows the overall MATLAB/Simulink diagram for the Direct Torque Control of Matrix Converter fed Induction Motor drive.

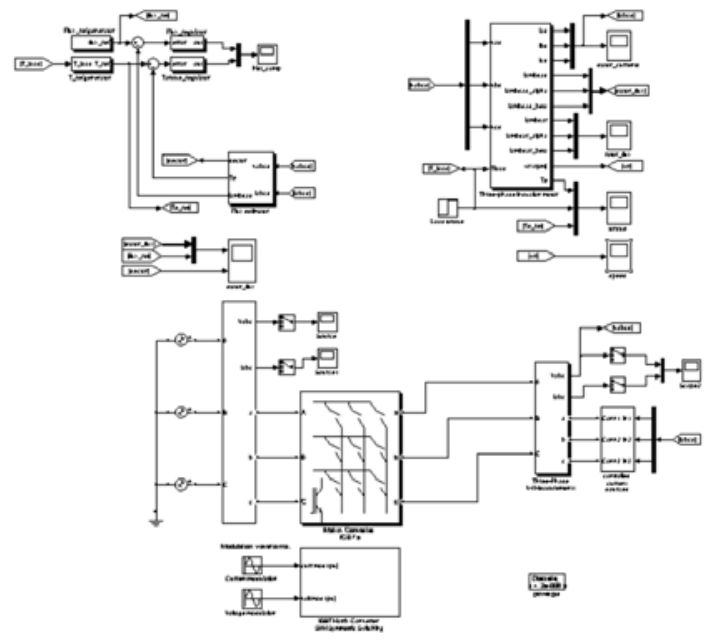

Fig. 4. Overall Simulation Model of Matrix Converter fed Induction Motor Drive

In order to control the speed of an induction motor, an reference value of flux and torque is being chosen initially and it is being compared with that of the torque and the flux, in terms of stator voltages and currents measured from the motor, which generates the flux and torque errors that properly selects the voltage vectors in order to drive the motor. A Matrix Converter is being used to run the motor, from which the faster torque response can be achieved.

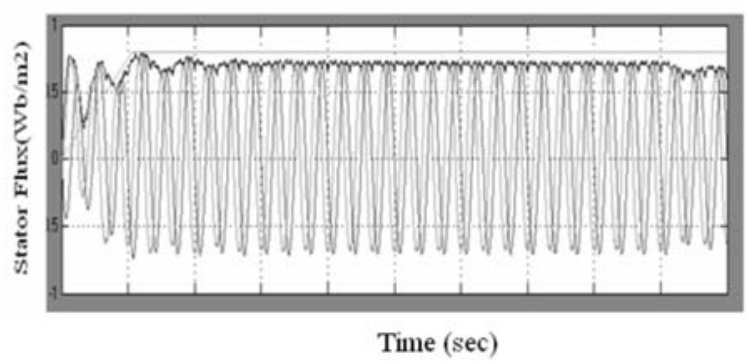

Fig. 5. Stator Flux of Induction Motor

Fig. 5 shows the variation of stator flux waveforms, where the stator flux is sinusoidal in nature, whose amplitude is about $0.7 \mathrm{wb} / \mathrm{m} 2$.

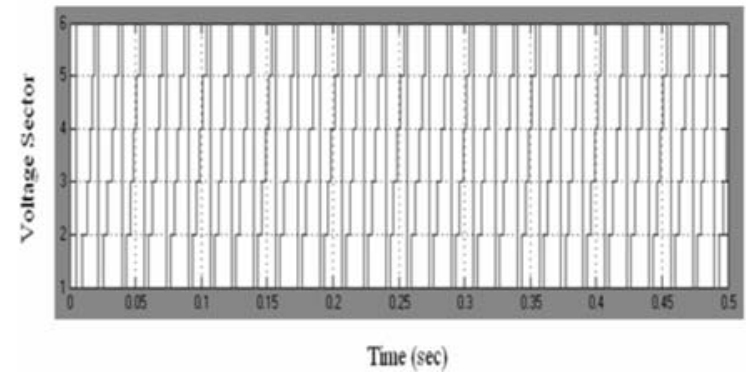

Fig. 6. Voltage Sectors of Matrix Converter

Fig .6 shows the voltage sector waveforms of the Matrix Converter, in which the proper voltage sectors are being selected from the look up table in order to drive the Induction motor. 


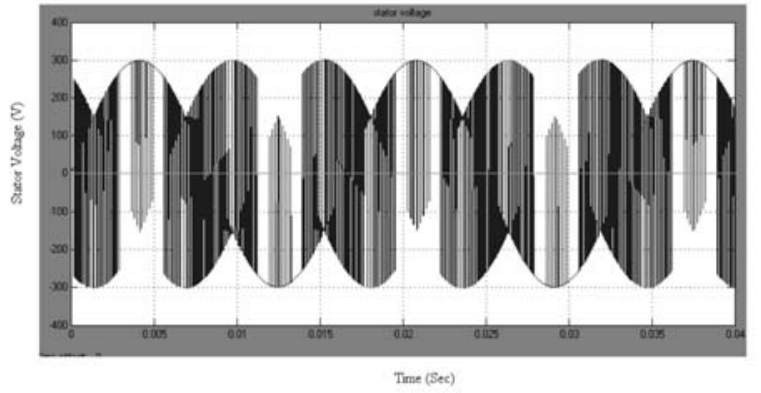

Fig. 7. Stator Voltage of Induction Motor

Fig.7 shows the stator voltage waveforms which is used to drive the induction motor, whose amplitude is about $300 \mathrm{~V}$, which is sufficient to drive the motor.

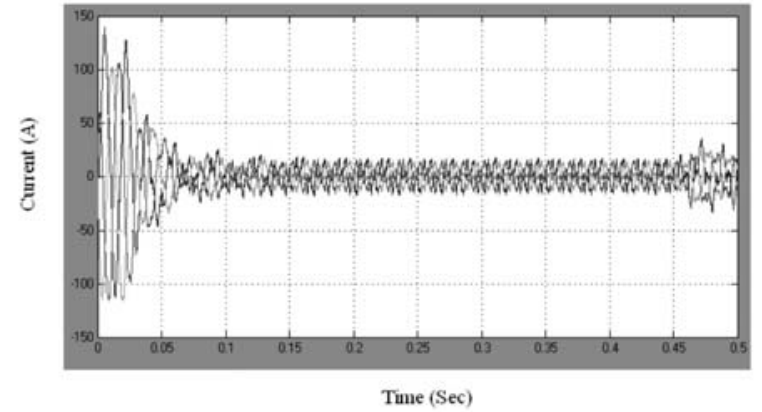

Fig. 8. Stator Current of Induction Motor

Fig. 8 shows the variation of stator current with respect to time where the initial starting current is about $25 \mathrm{~A}$ and then gradually decreases to about $15 \mathrm{~A}$, which avoids the heating of windings.

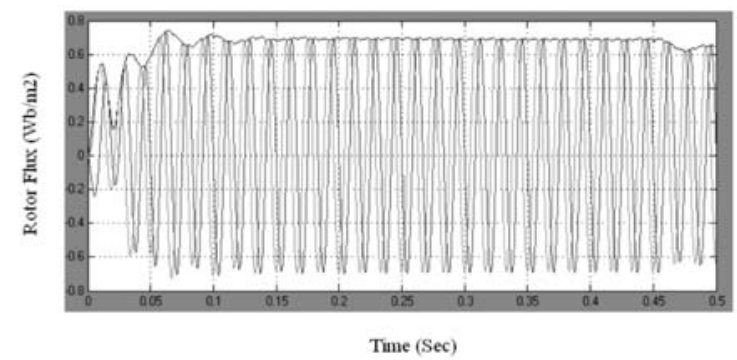

Fig. 9. Rotor Flux of Induction Motor

Fig. 9 shows the variation of rotor flux with respect to time, in which the rotor flux amplitude is about $0.7 \mathrm{wb} / \mathrm{m} 2$ and it is also sinusoidal as that of stator fluxes.

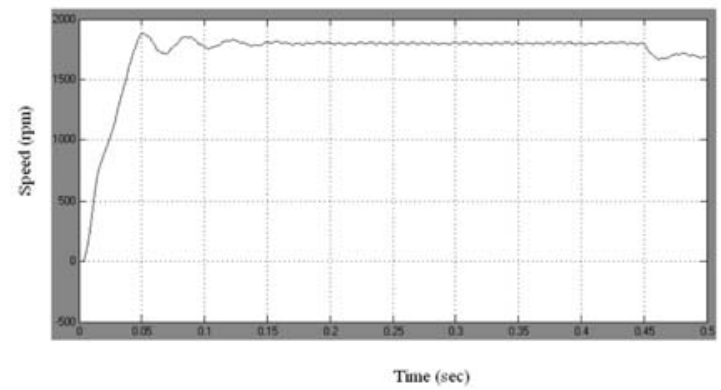

Fig. 10. Speed of Induction Motor

Fig.10 shows the variation of speed with respect to time. At the time of starting, the speed gradually increases and then maintains the constant speed of about 1900rpm.

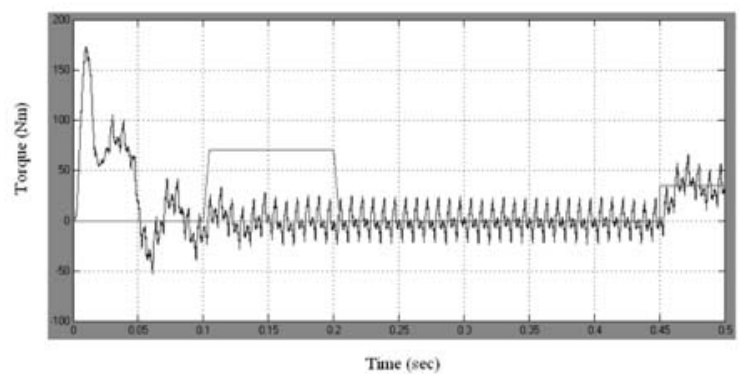

Fig. 11. Torque of Induction Motor

Fig.11 shows the variation of torque with respect to time. When the speed starts increasing, the torque gradually decreases to about $40 \mathrm{Nm}$.

\section{CONCLUSION}

In this paper, the matrix converter fed induction motor drive implemented by DTC is simulated. Based on the principles of the matrix converter and direct torque control, combined control strategy is presented, which can implement the real-time space vector modulation of converter and induction motor stator flux linkage oriented direct torque control. The equations show that the change of torque can be controlled by keeping the amplitude of the stator flux linkage constant and increasing the rotating speed of the stator flux linkage as fast as possible. The amplitude and rotating speed of the stator flux linkage can be controlled by selecting the proper stator voltage vectors. The torque and flux linkage reference are kept constant at the same level in order to reduce the torque ripples. The simulated results shows that induction motor drive fed by the matrix converters using direct torque control technique has reduced torque ripples and faster torque response. 


\section{REFERENCES}

[1] Casdei.D, Serra.G, Tani.A, "The Use of Matrix Converters in Direct Torque Control of Induction Machines", IEEE Transactions on Industrial Transactions, Vol 48, No.6, pp 1057-1064, Dec 2001.

[2] P. Wheeler, J. Rodriguez, J. Clare, L. Embringham, and A. Weinstein, "Matrix Converters: A Technology review," IEEE Trans. on Industrial Electronics, Vol. 49, No. 2, pp. 276-288, April 2002.

[3] D. Casadei, G.Grandi, G.Serra, A. Tani, "Switching Strategies in Direct Torque Control of Induction Machines," Proceedings in International Conference on Electrical Engineering, Paris, pp. 204-209, 5-8 September 1994.

[4] M. Depenbrok, "Direct Self-Control (DSC) of Inverter-Fed Induction Machine," IEEE Trans. on Power Electronics, Vol. 3, pp. 420-429, Oct. 1988.

[5] Takahashi, T. Noguchi, "A New Quick-Response and High Efficiency Control Strategy of an Induction motor," IEEE Trans. on Industrial Automation and Electronics, Vol. IA-22, No. 5, pp. 820-827 Sept./Oct. 1986.

[6] Bimal K.Bose, "Modern Power Electronics and Electric Drives" Englewood Cliffs, $2^{\text {nd }}$ Edition, New Jersey, Prentice Hall, 1986.

[7] Zhong.LI, Rahman.M, Hu.W, Lim.K "Analysis of Direct Torque Control in Permanent Magnet Synchronous Motor Drives", IEEE Trans on Power Electronics, Vol. 12, No. 3, May 1997.

[8] C.Ortega, P.Wheeler, "Sensorless Induction Motor Drives Fed by a Matrix Converter," IEEE Proceedings on Industry Applications Conference, Fourtieth IAS Annual Meeting, Vol.4, 2-6 Oct. 2005.

[9] Lascu.C, Boldea. I, Blaabjerg.F ,"A Modified Direct Torque Control for Induction Motor Sensorless Drive,"IEEE Trans on Automation and Electronics, Vol. 36, No. 1, pp. 122-130, Jan.-Feb 2000.

[10] Hong Hee Lee, Hoang M.Nguyen, Tae Won Chun, "Implementation of Direct Torque Control method using
Matrix Converter fed Induction Motor," Journal of Power Electronics, Vol.8, No.1, pp. 74-80, January 2008.

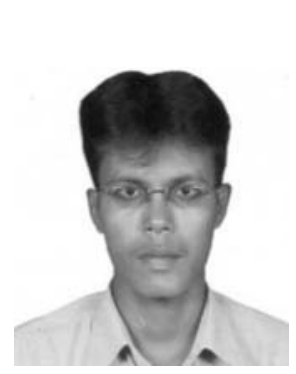

M.Suresh was born on 1988 in Tamilnadu, India. He received his B.E degree in Electrical and Electronics Engineering from Muthayammal Engineering College, Rasipuram, Affiliated to Anna University, Chennai in the year 2005. Currently, he is doing his Master's degree in Power Electronics and Drives in Bannari Amman Institute of Technology, Sathyamangalam, Affiliated to Anna University, Coimbatore. His area of interests includes Digital systems and Design, Sensorless control of Induction motor Drives.

J.Karpagam, She

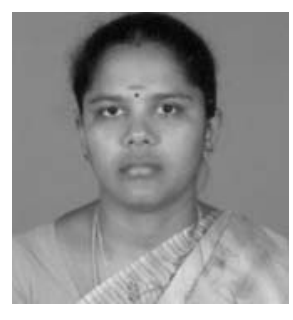
completed her Masters degree in the specialization of Power Electronics and Drives from Anna University Chennai, India. Presently she is working as Assistant Professor in the department of Electrical and Electronics Engineering at Bannari

Amman Institute of Technology Tamilnadu, India and she is in this profession since 1999. Currently she is pursuing her Ph.D. in the area of multilevel converters applications to AC Drives under Anna University Coimbatore. Her area of interest includes Power Electronics, DSP applications to Power Electronics and Wind Power Generation, Solid State Drives, Power Converters, AC \& DC drives. So far she has published around ten papers in national level and international conferences. 